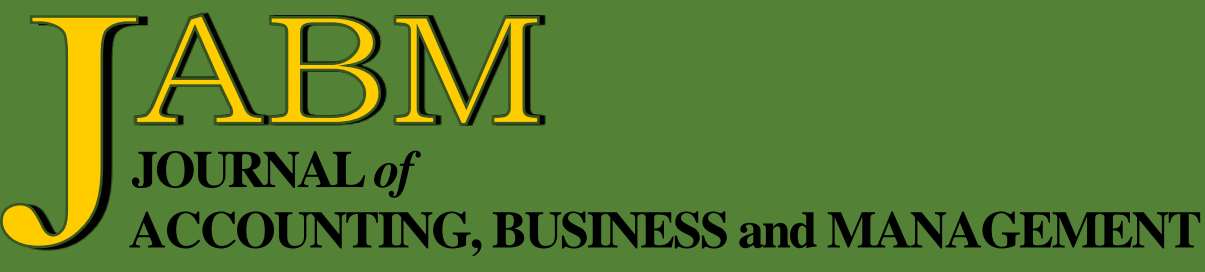

Towards Understanding the Effects of Web 2.0 at the Project Level Knowledge Management on Projects' Success

Anupam Kumar Nath

Sticky Costs and Expenses are not Alike: Mexican Reality

Luis Felipe Llanos Reynoso, César Vela-Beltrán-del-Río, and

José Luis Martínez-Berrones

Business Sustainability Through Environmental and Operational Management in Five Star Hotels in Amman, Jordan

Haitham Abdelrazaq, Taghreed Aljaffal, Pheroza Daruwalla, and

Karina Wardle

Impacts of Asset Utilization, Market Competition and Market

Distance on Stock Returns

Jeanne-Claire Patin, Matiur Rahman, and Muhammad Mustafa

Accounting Conservatism, Information Asymmetry and

Cash Holdings

Walid Shehata and Ahmed Rashed

An Investigation of the Relationship between Corporate Social Responsibility and Corporate Financial Performance in Egypt: The Mediating Role of Information Asymmetry

Nancy Mohamed and Ahmed Rashed

The Impact of Regulatory Capital and Bank Characteristics on the Relationship between Bank Competition and Risk Taking in the Banking System

Eman Abdel-Wanis

Firm Size, Firm Age, and Firm Profitability: Evidence from China Md. Jahidur Rahman and Liu Yilun 
Journal of Accounting, Business and Management (JABM) vol. 28 no. 1 (2021) 1-13

\title{
Towards Understanding the Effects of Web 2.0 at the Project Level Knowledge Management on Projects' Success
}

\author{
Anupam Kumar Nath*
}

\begin{abstract}
Web 2.0 is in use for knowledge management (KM) in organizations at different levels. In this research, we study the relationship between the use of Web 2.0 in knowledge management (KM) and its effect on the Project's success when Web 2.0 is in use for the project's KM. We also study the impact of project-level KM context variables on this relationship. Findings show that the uses do not have a decisively positive effect.
\end{abstract}

Keywords: Web 2.0, knowledge management, group, and case study.

\section{INTRODUCTION}

Knowledge management (KM) is the process through which organizations generate value from their intellectual and knowledge-based assets (Levinson, 2006). Currently, organizations utilize internet-based technologies as KM tools to manage organizational knowledge (Zeng et al., 2015). A newer generation of internet-based collaborative tools, commonly known as Web 2.0, has increased in popularity, availability, and power in the last few years in organizations (Zeng et al., 2015; Husin et al., 2016). Web 2.0 is a set of internet-based applications that harness network effects by facilitating collaborative and participative computing (Anderson, 2007; O'Reilly, 2007; Parameswaran \& Whinston, 2007; and Richards, 2009). Web 2.0 has the potential to deliver rich peer-to-peer interactions among users, enable collaborative value creation across business partners, and create dynamic new services and business models (Ganesh \& Padmanabhuni, 2007). Web 2.0 technologies include Wiki, blog, RSS, aggregation, mashups, audio blogging and podcasting, tagging and social bookmarking, multimedia Sharing, and social networking. Realizing this potential for effective KM, a few leading IT organizations have adopted Web 2.0 for KM at the project level. However, it is not properly understood how effective they are at the project level KM. In our study, we want to understand the effect of Web 2.0 based KM on a project's success. Hence, the following research question guides our research:

How does the use of Web 2.0 for KM affect a project's success?

In this research, we adopt a qualitative positivist case study based research approach to confirm the relationships between the use of Web 2.0 technology and KM, and its effectiveness. Our approach essentially helps us to examine the proposed relationships as well as identify noteworthy interesting aspects pertinent to the hypotheses through the interpretation of the qualitative data.

The finding of our research addresses a gap in the existing literature on KM and can help the organizations to have a better understanding of the effective use of Web 2.0 for $\mathrm{KM}$ at the project level.

\footnotetext{
* Assistant Professor, Georgia Gwinnett College, School of Business, University Center Lane, Lawrenceville, GA 30043. Phone office/cell: 404-938-3378. Web site: www.ggc.edu. E-mail: anath@ggc.edu.
} 


\section{LITERATURE REVIEW}

Existing studies have assessed the effects of $\mathrm{KM}$ on projects in two prominent ways: the project output's success (Fedor et al., 2003) and team performance (Janz \& Prasarnphanich, 2003). Both have been measured in the same study, too (Akgün et al., 2005). An overview of these studies has been provided in Table 3. One criterion that has been used to determine a project's success is goal achievement (Fedor et al., 2003; Akgün et al., 2005). For example, Akgün et al. (2005), in their study to identify the antecedents of creating an effective transactive memory for projects' KM, measured the effects of $\mathrm{KM}$ in terms of success of the new product created in a project using financial indicators (e.g., return on investment (ROI)) and non-financial indicators (e.g., satisfaction of management and customers with the new product). They found that KM positively influenced product success. Effects of $\mathrm{KM}$ on a project have also been measured in terms of project completion time (Mitchell, 2006). Specifically, Mitchell (2006) found that effective KM can reduce delays and help to finish a project as per schedule.

KM's effect on projects has also been studied in terms of performance of a project team, measured in terms of efficiency (i.e., the efficiency of team's operation), effectiveness (i.e. quality of the work a team produces) and timeliness (i.e. a team's adherence to schedule) (Janz \& Prasarnphanich, 2003). Effects of KM on a project team's performance have also focused on a team's learning measured by the extent to which KM has helped a team gain knowledge to improve performance (Janz \& Prasarnphanich, 2003); and how much of that knowledge has been transferred to later projects (Akgün et al., 2005). Both studies found a positive influence of $\mathrm{KM}$ on dependent variables establishing the importance of $\mathrm{KM}$ for projects.

Gold et al. (2001) argue that objective measures such as financial indicators are significantly confounded by many uncontrollable business, economic, and environmental factors. Hence, using measures less confounded by uncontrollable factors will provide a clearer insight into the value-added aspect of KM capability. In this research, we are interested in learning how Web 2.0 facilitated KM affects a project team's performance in terms of efficiency, efficacy, timeliness and team learning, as well as KM's effect on the project's success.

\subsection{Web 2.0 for KM and Effective Transactive Memory System}

Alavi and Tiwana (2002) pointed out that knowledge networking in groups or teams is effective if members know who has the required knowledge and expertise, where the knowledge and expertise are located, and where and when they are needed (Salas et al., 2002). The idea of such knowledge networking and interpersonal awareness of others' knowledge has been studied and is referred to as the transactive memory system (TMS) (Hollingshead, 1998). In TMS, individuals who are in continuing relationships, utilize each other as memory sources or aids to supplement their own limited and unreliable memories and knowledge (Wegner et al., 1985). A TMS occurs when two or more people cooperatively store, retrieve, and communicate information and knowledge, and it provides a knowledge network among individuals, thereby allowing the interchange of data, information, and knowledge. TMS has three principal components (Akgün et al., 2005):

a) Specialization: the differentiated structure of member knowledge, which is facilitating the availability of different sorts of knowledge, especially complimentary.

b) Credibility: members' beliefs about the accuracy and reliability of other members' knowledge. 
c) Coordination: effective and orchestrated knowledge processing.

We believe that Web 2.0 technology has the potential to deliver all three components at the project level due to the following:

First, on Wiki, a Web 2.0 technology, people with different knowledge base and expertise can share their knowledge (Hohman \& Saiedian, 2008). We found in our exploratory study that Wiki is in use at the project level in all three organizations. Wiki is in use to facilitate the knowledge sharing of different people with diverse skills and expertise in a project team.

Second, Wiki can facilitate the asynchronous, simultaneous collaboration of multiple people by means of which knowledge can evolve through conversation (Wagner, 2006). The version-control feature of Wiki is also an advantageous feature of IT projects as in addition to storing the information; it helps to identify the evolution of knowledge and to backtrack if required (Louridas, 2006). All these features of Wiki can help to ensure effective coordination (Brown et al., 2007).

The positive influence of a TMS on team performance is well established in the extant literature (Yoo \& Kanawattanachai, 2001). Akgün et al. (2005) found that effective TMS positively influences the success of a project's product. A product's success refers to the performance of the product (Cooper \& Kleinschmidt, 1987), which can be measured in terms of its acceptance by the stakeholders such as management and customers (Akgün et al., 2005). As we assert that Web 2.0 technology can efficiently facilitate TMS, we posit that the use of Web 2.0 for KM also have a similar positive effect on a project team's learning and a product's success.

$\mathbf{H}_{1}$ : Web 2.0 technology for KM in a project positively affects the project's product success.

\subsection{Role of Project-Level Context Variables}

The members of a project team are involved in that project's KM and, therefore, their familiarity with each other is a critical project-level KM context variable. Project team members' familiarity can be defined as the degree of prior interaction between team members. Gruenfeld et al. (1996) empirically found that the team members who were familiar with each other were significantly more successful at sharing than a team of strangers. Janz (1999) also highlighted the importance of the team environment in creating effective KM in which team members are familiar with each other.

In addition to team members' familiarity, team-level studies have also noted the importance of team stability in effectively allowing the interchange of data, information, and knowledge in project teams. Research has found that the project team's stability has a positive impact on team learning and overall project success (Akgün et al., 2002). Blau (1964) highlighted reciprocity as a benefit for individuals who engage in social exchange. Several studies have empirically shown that individuals participating in online $\mathrm{KM}$ activities perceive reciprocity as a strong motivating factor (Kankanhalli et al., 2005). Based on the results of existing studies, we can infer that if a project team is stable and its team members are familiar with each other, then there will be a higher sense of reciprocity. This higher reciprocity will have a positive effect on team members' participation in Web 2.0-based project-level KM, and this will, in turn, positively affect the different project-level outcome variables. Another context variable that plays a role in the effective sharing of information in a project team is a team leader's ability to provide an open environment for communication (Fedor et al., 2003). A team leader sets up a tone for the whole team by providing ongoing directions and 
guidance (Nemeth et al., 1992; Nath, 2012). A team leader is also the key person to establish the information sources both within and outside the team for his team.

Moreover, a team's leader essentially facilitates or constraints free flow of information and ideas for his team's KM (Davenport et al., 1998). Hence, to use Web 2.0 tools for a project team's KM, it is important that the project team leader facilities an open environment where project team members participate in Web 2.0 based KM activities to share their knowledge. Therefore, we assert that a project team leader's ability to provide an environment for communication and information sharing will increase team members' participation in their team's Web 2.0 based KM activities and that will, in turn, positively affect the different project-level outcome variables.

Based on this conjecture, we consider these context variables positively affect the relationship between the uses of Web 2.0 for KM and a project-level outcome variable. We depict the relationships through the following hypotheses and model.

$\mathbf{H}_{1 \mathrm{a}}$ : project team members' familiarity with each other positively affects the relationship between the use of Web 2.0 technology for KM at the project level and success of a project's product.

$\mathbf{H}_{1 \mathrm{~b}}$ : stability of the project teams positively affects the use of Web 2.0 technology for $\mathrm{KM}$ at the project level and success of a project's product.

$\mathbf{H}_{1 \mathrm{c}}$ : team leadership positively affects the use of Web 2.0 technology for $\mathrm{KM}$ at Figure1

the project level and success of a project's product.

Research Model Based on Hypotheses

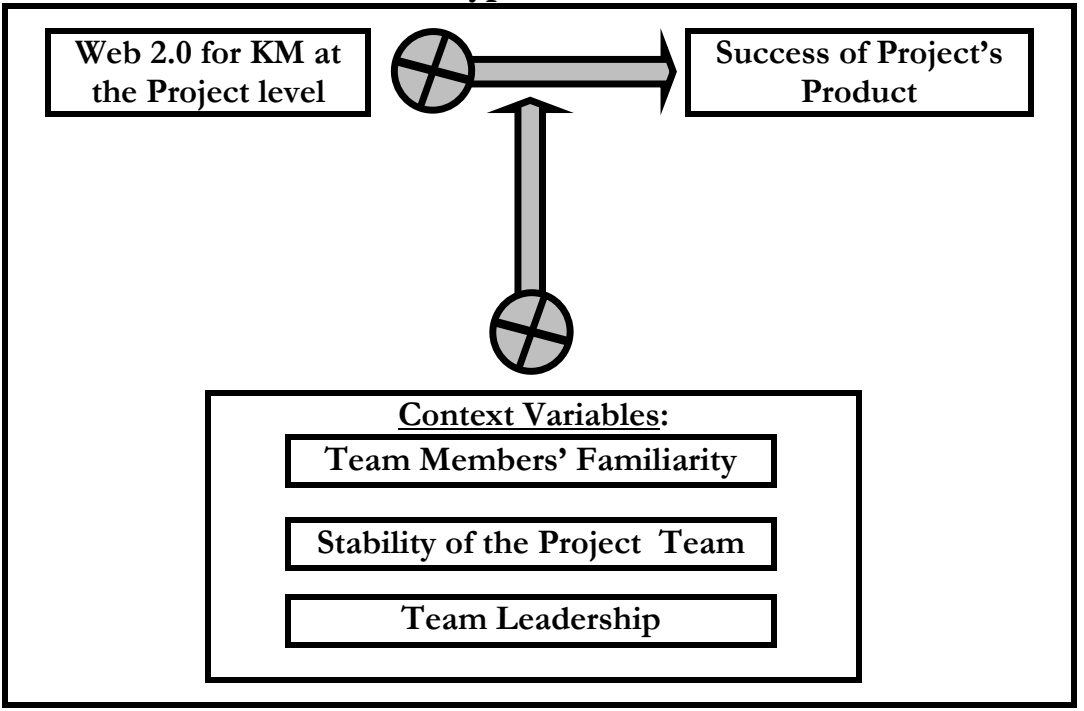

\section{RESEARCH SAMPLE AND METHODOLOGY}

A positivist case study research can be used to test theory(s). We deploy a qualitative positivist case-study approach to test the hypotheses. Our adoption of positivism is consistent with the views that are held by scholars in the fields of organizational studies (Eisenhardt, 1989; Lee, 1991), and information systems (Lee, 1989; Orlikowski \& Baroudi, 1991; and Lee at al., 1999; and Sarker \& Lee, 2002), and follows a similar path. "Hypothetico-deductive logic" is central to the world of positivist research today (Lee et al., 1999), which necessarily is a synthesis of three traditions: empiricist, rationalist, and critical rationalist (Sarker \& Lee, 2002). There is an empiricist influence in our positivist approach that is reflected in the rigor of our 
research process, drawing mainly on Yin (1994). The rationalist and the criticalrationalist traditions are reflected in the use of pattern matching to deductively test falsifiable statements derived from the literature (Sarker \& Lee, 2002).

As this research is principally positivist in nature, using clearly defined methodological guidelines we satisfy the four criteria of rigor (Shanks, 2002): construct validity, internal validity, external validity, and reliability (Lee, 1989; Yin, 1994). In the following table, we summarize how we address the requirements of the positivist casestudy method.

Table1

Steps to Achieve Rigor of the Study as Per Qualitative Case-Research Criteria

\begin{tabular}{ll}
\hline Rigor Criterion & $\begin{array}{l}\text { Guidelines to achieve rigor based on Lee (1989), Yin (1994), } \\
\text { and Sarker and Lee (2002) }\end{array}$ \\
\hline Construct Validity & $\begin{array}{l}\text { Use of multiple sources of evidence } \\
\text { Review of the report by the key informants } \\
\text { Chain of evidence }\end{array}$ \\
\hline Internal Validity & Pattern matching \\
\hline Reliability & $\begin{array}{l}\text { Case-study database (consists of case-study notes, documents, } \\
\text { and narratives) creation and maintenance } \\
\text { Case-study protocol }\end{array}$ \\
\hline External Validity & $\begin{array}{l}\text { Increased degree of freedom } \\
\text { Replication logic }\end{array}$ \\
\hline
\end{tabular}

Based on this plan, we collect data to test the proposed hypotheses. According to the recommendations by Glaser and Strauss (1967), George and McKeown (1985), Eisenhardt (1989), and Yin (2003) we based the case selection for our study on two factors- theoretical background and feasibility. We will study projects from three organizations that used Web 2.0 for KM at the project level for more than 10 years.

\subsection{Selection of Cases}

Case selection is a critical aspect of conducting a case study. Not only does the population define the set of entities from which the research sample is to be drawn, but the selection of an appropriate population also controls extraneous variation and helps to define the limits for generalizing the findings (Eisenhardt, 1989). According to the recommendations by George and McKeown (1985), Eisenhardt (1989), and Yin (2003), we based the case selection for our study on two factors - theoretical background and feasibility.

The first factor includes theoretical relevance, purpose, similarities, and differences across data sources concerning the data sources' appropriateness for the study. In our case, we want to study the uses and effects of Web 2.0 based KM at the group levels. Hence, we selected three organizations which have been using Web 2.0 for KM at group levels for a sufficient length of time (in this case more than ten years) to identify and understand the effects of Web 2.0 based KM. All three organizations are leading firms in their respective fields in the IT industry and have branches or offices in many countries. However, they are different in terms of the type of business they conduct within the IT industry. The organization I is mainly involved in IT services. Organization B manufactures and sells computer hardware and software with a focus on the latter. Organization $\mathrm{C}$ concentrates on networking and communications technology and services. For groups, we selected different functional units, such as research, design, and testing groups. 
The second factor, feasibility, was largely determined by each organization's willingness to participate in the study and to provide the required information. In our research, the organizations we selected had to be willing to provide us the necessary information and share their experience so that we could study the uses and effects of Web 2.0 for KM.

\subsection{Brief Description of the Selected Organizations}

The organization I is an information technology services company headquartered in India. It is one of the largest IT companies in India with more than 100,000 professionals. The company has offices in 22 countries and development centers in India, China, Australia, UK, Canada, and Japan. In 2009, organization I was identified as one of the best performing and most innovative companies in the software and services sector in the world by Forbes and Business Week. The organization I has a strong focus on $\mathrm{KM}$ and has won several prestigious awards for its organization-wide $\mathrm{KM}$ efforts. It has been using Web 2.0 for KM for approximately twelve years.

Organization B is a multinational computer, technology, and IT consulting corporation. Organization B is one of the Fortune 100 companies. The company is one of the few information technology companies with a continuous history of being recognized as a leading IT company, dating back to the 19th century. Organization B manufactures and sells computer hardware and software, and offers infrastructure, hosting, and consulting services in areas ranging from mainframe computers to nanotechnology. The company has more than 400,000 employees worldwide, with sales exceeding 100 billion US dollars. The employees are scientists, engineers, consultants, and sales professionals in over 170 countries. Organization B has been using Web 2.0 for KM since 2003-2004.

Organization $\mathrm{C}$ is an American multinational corporation that designs and sells consumer electronics, and networking and communications technology and services. Organization $\mathrm{C}$ has been identified as one of the Fortune 100 companies. Organization $\mathrm{C}$ has more than 70,000 employees and annual revenue of more than 36 billion dollars. It has more than 190 branches worldwide and has been using Web 2.0 for KM for approximately ten years.

\subsection{Data Collection and Analysis}

Our principal data collection method was semi-structured interviews. We interviewed six managerial level professionals from the selected organizations. All interviewees had experiences using Web 2.0 for KM at different levels. Therefore, they were in a position to describe how Web 2.0 is used for KM at the group, project, and individual levels in their respective organizations and their experience while using it at these levels. Each interview had an average duration of forty-five minutes to an hour. We interviewed one person from organization $\mathrm{C}$ twice. He had a significant amount of information to share, and it was not possible to gather all the information in one interview. Later, we also conducted several short interviews with these interviewees to clarify some aspects of their responses during the first round of interview. We recorded these interviews whenever possible and transcribed all sessions before starting the data analysis. To enhance the validity of the answers, whenever possible, we verified summaries of the major findings with the interviewee after the interview session.

Furthermore, to ensure consistency and reliability, we used a structured interview guide for all the interviews. The interview guide includes several open format questions based on our research framework and the identified effects of KM at different levels from the existing literature. However, to allow the participants flexibility in their 
responses, we used open-ended questions. We also included questions on organizational and interviewee demographics to obtain a complete understanding of the firms and individuals interviewed.

As a second data source, wherever possible, we also investigated the Web 2.0 technologies (e.g., blogs, Wikis, social networking platforms) which the organizations use for KM. Existing literature suggests that it is preferable to have multiple investigators in such case studies. Hence, wherever possible, we made sure that at least two researchers were present for the interviews.

A significant characteristic of our research is the overlap of data analysis and collection, and we achieve this through field notes. Overall, we followed the same guidelines provided by Lee (1989), Sarker and Lee (2002), and Yin (2003) to achieve rigor in our case study.

\section{EMPIRICAL RESULTS}

We did not find support for the hypothesis that the use of Web 2.0 technology for $\mathrm{KM}$ at project level positively affects the success of a project's product. While interviewees thought that the use of Web 2.0 for KM could help a project especially in terms of knowledge sharing, they did not think that it could significantly affect the success of a project's product measured in terms of acceptance by management and customers.

Interviewees, who had used Web 2.0 in their projects' KM, stated that in many cases, the knowledge transferred from previous projects helped the project team significantly in ongoing projects. Web 2.0 tools also helped in knowledge sharing among team members. However, interviewees emphasized that the success of a project's product is not significantly affected by advantages gained from the use of Web 2.0 for projects' KM. For example, an interviewee from organization B stated,

No way. So many factors are associated with a project, and each project is so much different from the others and poses different challenges that these tools alone cannot make a big difference.

Similarly, an interviewee from organization $\mathrm{C}$ stated,

"... they sure do help quite a bit in different ways. We have talked about

those, right? But, I would not say that these tools affect the success of a

product significantly. You know so many other factors are there".

Our results show that while the use of Web 2.0 for a project's KM helps in the transfer of knowledge between projects, it does not significantly affect the success of that project's product.

Managing project knowledge includes the creation of a system to organize project information and simplify access use of project data by the team (Linman, 2011). While this management of project's knowledge is essential (Linman, 2011), other factors associated with a project, such as requirement changes and team members' performance, significantly affect the success of that project (Belassi \& Tukel, 1996). The interviewees expressed similar views. The interviewees thought while the use of Web 2.0 can positively affect a project's KM, it alone cannot significantly affect the success of a project because other factors have more significant impacts.

Our finding suggests that management should consider Web 2.0 for project-level $\mathrm{KM}$ to facilitate knowledge transfer and reuse in projects more effectively. If the other factors such as requirement changes do not come into play, then Web 2.0 based KM can positively affect a project's success. 


\subsection{Use of Web 2.0 for KM, Success of a Project's Product and Context Variables}

We studied three project-level KM context variables: team members' familiarity with each other, the stability of the project team, and the team leader's ability to provide a team environment for open communication. While there are some indications that these context variables are important for the Web 2.0-based KM to be effective at the project level, we could not conclude that the context variables significantly affect the relationships between the use of Web 2.0 for a project's KM and success of a project's product.

We could not draw any definite conclusion regarding the hypothesis that project members' familiarity with each other positively affects the relationship between the use of Web 2.0 for KM and a project's product's success. Our results were inconclusive as interviewees could not clearly identify the effect of the project team members' familiarity with the success of a project's product in the Web 2.0 based KM environment.

We found that interviewees did not think that use of Web 2.0 for KM at project level significantly affects the success of a project's product, but rather they pointed to other factors that significantly affect the success of a project's product. Consequently, the interviewees could not clearly identify how and to what extent project team members' familiarity would affect the use of Web 2.0 for KM at the project level and which in turn would positively affect the success of a project's product. As described by an interviewee from organization $\mathrm{C}$,

"Hard to say as we are always more about worried things like sudden changes in the project requirement".

While we could not draw any definite conclusion regarding the effect of project team members' familiarity with each other on the relationship between the use of Web 2.0 for KM and a project's product's success, the existing literature emphasize the importance of project team members' familiarity in team's KM (Janz, 1999). Therefore, while we encourage management to consider project team members' familiarity with each other as an aspect in forming project teams, we do not assert that it would have a significant effect on the success of a project's product in Web 2.0 based project level KM environment.

Another project level context variable that we studied is the stability of the project team. We could not find enough evidence in the interviewees' responses to draw a definite conclusion regarding the hypothesis that a project team's stability affects the relationship between the use of Web 2.0 for KM and a project's product's success. Our hypothesis testing result is inconclusive as interviewees responded that the effect of a project team's stability on the success of a project's product in the Web 2.0 based $\mathrm{KM}$ environment is not clearly identifiable if there is any effect at all.

In the responses of the interviewees, it was evident that they were more concerned about other factors, such as abrupt changes in the requirements by the client, that affect the success of a project's product measured in terms of acceptance by management and customers. Such responses led us to the conclusion that the stability of the project team does not have any significant effect on the success of a project's product in Web 2.0 based KM. However, when asked whether this is a valid conclusion, the interviewees did not concur. For example, an interviewee from organization $\mathrm{C}$ responded,

"I would not say so. Stability (i.e., the project team's stability) very well might have a positive effect on the use of Web 2.0 (i.e., Web 2.0 based 
$\mathrm{KM})$. It is just that other factors are the ones we notice more and Web 2.0 things are sort of new".

While extant literature points out the importance of a project team's stability on the project level KM and subsequent outcome variables (Akgün et al., 2005), we could not draw any definite conclusion regarding the effect of project team's stability on success of a project's product in Web 2.0 based project level KM. Akgün et al. (2002) suggested that project team stability contributes to a positive outcome in the project if there are no exceptional circumstances such as an unexpected change in the project requirements or scarcity of the required skills. In accordance with Akgün et al. (2002, 2005) findings, we encourage management to form stable project teams, but we do not infer that stability would have a significant effect on the success of a project's product in Web 2.0 based project level KM environment.

We also studied project managers' ability to provide an open environment for communication as project-level context variables. We could not draw a specific conclusion regarding the hypothesis that a project manager's ability to provide an open environment for communication affects the relationship between the use of Web 2.0 for KM and a project's product's success. Interviewees responded that the effect of a project manager's ability to provide an open environment for communication in the success of a project's product in the Web 2.0 based KM environment was not clearly identifiable to them due to the existence of many external and internal factors that affect a project's product success. Therefore, we could not draw any definite conclusion regarding the hypothesis.

All interviewees were unanimous that project managers play a very important role in the implementation of Web 2.0 based KM at the project level. As mentioned by an interviewee from organization $\mathrm{C}$,

"His (the project manager) perception towards that (Web 2.0 based KM) is very critical. When I have to work with different managers in different projects, it becomes very evident that how and to what extent a project team is using KM depends largely upon the project manager".

Another interviewee from organization B stated the following regarding his project manager's role to facilitate open communication among team members,

"Project managers do not usually interfere. Therefore, whenever needed, we (the team members) just communicate with each other, set up a WikiB page, and so on".

While interviewees thought that the ability of project manager to provide an open environment for communication is important for a project's KM, they could not draw any definite conclusion about how important it would be in the success of a project's product. Once again, interviewees mentioned the existence of many different factors that affect the success of a project's product as the reason why they could not comment specifically about the role of a project manager in the relationship between use of Web 2.0 for KM and success of a project's product.

A team's leader is responsible for facilitating the free flow of information and ideas in a team (Davenport et al., 1998). Therefore, it is important that the project team leader facilities an open environment to encourage project team members to participate in Web 2.0 based KM activities to share their knowledge and make Web 2.0 based KM effective. While through our case study we could not confirm the hypothesis that a project manager's ability to provide an open environment for communication affects the relationship between the use of Web 2.0 for KM and a project's product's success, 
the findings of our study do suggest that a project manager should provide an open environment for communication to make the project level KM functional.

Table 2

The findings of our study are in Table 2 .

\section{Summary of the Proposition Testing Results}

\begin{tabular}{lll}
\hline $\begin{array}{l}\text { P}_{1} \text { Project } \\
\text { product's }\end{array}$ & Not & Use of Web 2.0 for KM can \\
success & supported & help a project, especially in \\
& terms of knowledge sharing. \\
& Use of Web 2.0 for the \\
& project's KM cannot signi- \\
& ficantly affect the success of \\
& a project's product measu- \\
& reed in terms of acceptance \\
& by management and \\
& customers.
\end{tabular}

Management ought to

consider Web 2.0 for project-

level KM to effecttively

facilitate knowledge transfer and reuse in projects.

The management and the project team members should not expect to produce a successful product due to the Web 2.0 based KM alone.

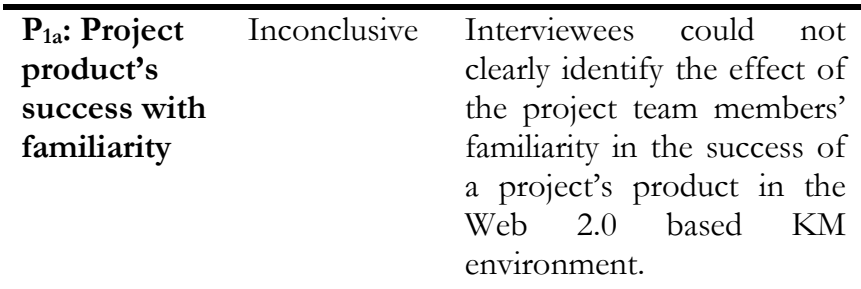

$\mathbf{P}_{1 \mathrm{~b}}$ : Project $\quad$ Inconclusive
product's
success with
stability

Effect of a project team's stability in the success of a project's product in the Web 2.0 based KM environment is not a clearly identifiable as there are oThe familiarity of the project team members with each $\mathrm{O}$ ther should be used a criterion in project team formation to facilitate knowledge sharing even though it might not have a significant effect the success of project's product.

Stability in a project team is desired only if there are no major changes in the project setup, such as changes in project requirements. ther factors are more prevalent in affecting the success of a project's product.

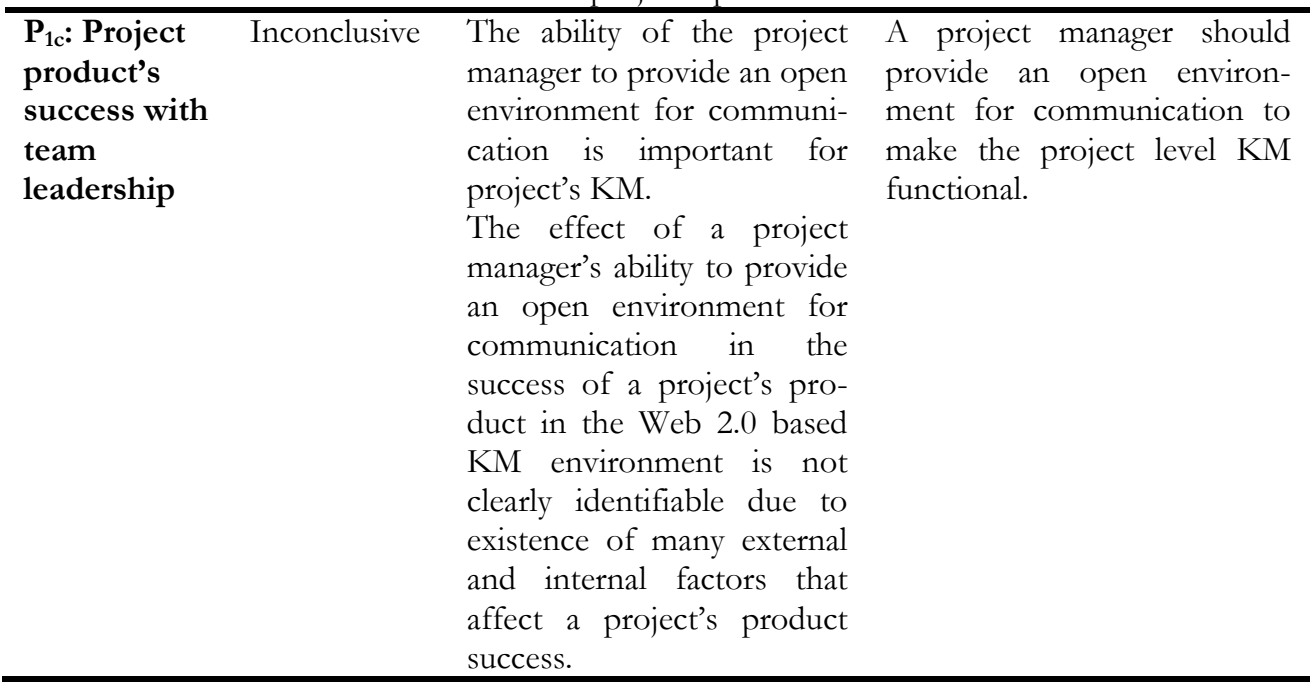




\section{CONCLUSION}

Web 2.0 has gained widespread popularity at the consumer level. However, it is still not well-understood how Web 2.0 can be effectively used for KM by enterprises. Our research addresses one aspect of this gap in the literature by studying the effects of using Web 2.0 for KM at the project level. We also study the effects of the context variables. Our finding shows that while the use of Web 2.0 for KM at the project level has some positive influence, the impact is not enough to draw any definitive conclusion. We believe this study will address a gap in the literature as well as help the managers to make effective use of Web 2.0 for project-level KM. In the future, we would like to extend this study to the various levels in the organization to understand the overall impact of Web 2.0 based KM.

\section{REFERENCES}

Anderson, P. (2007). What is Web 2.0? Ideas, technologies and implications for education (pp. 164). JISC Technology \& Standards Watch. Retrieved April 17, 2019, from http://www.jisc.ac.uk/media/documents/techwatch/tsw0701b.pdf.

Akgün, A. E., Byrne, J., Keskin, H., Lynn, G. S., \& Imamoglu, S. Z. (2005, December). Knowledge networks in new product development projects: A transactive memory perspective. Information \& Management, 42(8), 1105-20.

Akgün, A., Lynn, G., \& Reilly, R. (2002). Multi-dimensionality of learning in new product development teams. European Journal of Innovation Management, 5(2), 57-72.

Alavi, M., \& Tiwana, A. (2002). Knowledge integration in virtual teams: The potential role of KMS. Journal of the American Society for Information Science \& Technology, 53(12), 1029-1037.

Belassi, W., \& Tukel, O. I. (1996, June). A new framework for determining critical success/failure factors in projects. International Journal of Project Management, 14(3), 141-151.

Blau, P. M. (1964). Exchange and power in social life. New York: Wiley.

Brown, K. W., Ryan, R. M., \& Creswell, J. D. (2007, October). Mindfulness: Theoretical foundations and evidence for its salutary effects. Psychological Inquiry, 18(4), 211237.

Cooper, R. G., \& Kleinschmidt, E. J. (1987). New products: What separates winners from losers? Journal of Product Innovation Management, 4(3), 169-84.

Davenport, T. H., De Long, D. W., \& Beers M. C. (1998, Winter). Successful knowledge management projects. Sloan Management Review, 46(6), 85-88

Eisenhardt, K. M. (1989). Building theories from case study research. Academy of Management Review, 14(4), 532-550.

Fedor, D. B., Ghosh, S., Caldwell, S. D., Maurer, T. J., \& Singhal, V. R. (2003, August). The effects of knowledge management on team members' ratings of project success and impact. Decision Sciences, 34(3), 513-539.

Ganesh, J., \& Padmanabhuni, S. (2007, August 9-12). Web 2.0: Conceptual framework and research directions. $13^{\text {th }}$ Americas Conference on Information Systems, AMCIS 2007, Keystone, Colorado, USA. Proceedings: 332.

George, A. L., \& McKeown, T. J. (1985). Case studies and theories of organizational decision making. In R. F. Coulam \& R. A. Smith (Eds.), Advances in information processing in organizations (2nd ed., pp. 21-58). Greenwich, Conn.: JAI Press. 
Glaser, B. G., \& Strauss, A. L. (1967). The discovery of grounded theory: Strategies for qualitative research. New Brunswick, USA \& London (UK): Aldine Transaction, A Division of Transaction Publisher.

Gold, A. H., Malhotra, A., \& Segars, A. H. (2001, June). Knowledge management: An organizational capabilities perspective. Journal of Management Information Systems, 18(1), 185-214.

Gruenfeld, D. H., Mannix, E. A., Williams, K. Y., \& Neale, M. A. (1996). Group composition and decision making: How member familiarity and information distribution affect process and performance. Organizational Behavior \& Human Decision Processes, 67(1), 1-15.

Hohman, J., \& Saiedian, H. (2008, August). Wiki customization to resolve management issues in distributed software projects, Crosstalk: The Journal of Defense Software Engineering, 21(8), 18-22.

Hollingshead, A. B. (1998, March) Retrieval processes in transactive memory systems. Journal of Personality \& Social Psychology, 74(3), 659-671.

Husin, H., Evans N., \& Deegan, G. (2016, March). Achieving adoption and effective usage of Web 2.0 among employees within Australian government organizations. Journal of Systems \& Information Technology, 18(1), 41-63.

Janz, B. D. (1999). Self-directed teams in IS: Correlates for improved systems development work outcomes. Information \& Management, 35(3), 171-192.

Janz, B. D., \& Prasarnphanich, P. (2003). Understanding the antecedents of effective knowledge management: The importance of a knowledge-centered culture. Decision Sciences, 34(2), 351-384.

Kankanhalli, A., Tan, B. C. Y., \& Wei, K.-K. (2005, March). Contributing knowledge to electronic knowledge repositories: An empirical investigation. MIS Quarterly, 29(1),113-143.

Lee, A. S. (1989, February). Case studies as natural experiments. Human Relations, 42(2), 117-137.

Lee, C. M. C., Myers, J., \& Swaminathan, B. (1999). What is the intrinsic value of the dow? The Journal of Finance, 54(5), 1693-1741.

Levinson, M. (2006). The ABCs of KM. CIO Magazine. Retrieved November 25, 2006, from http://www.cio.com/research/knowledge/edit/kmabcs.html.

Linman, D. (2011). Project knowledge management- the importance of managing project knowledge. Retrieved April 17, 2021, from https://mymanagementguide.com/projectknowledge-management-the-importance-of-managing-project-knowledge/.

Louridas, P. (2006, April). Using wikis in software development. IEEE Software, 23(2), 88-91.

Mitchell, V. (2006). Knowledge integration and information technology project performance. MIS Quarterly, 30(4), 919-939

Nath, A. (2012). Web 2.0 technologies for effective knowledge management in organizations: A qualitative analysis. Unpublised Ph.D. Dissertation, the Faculty of the Graduate School at the University of North Carolina at Greensboro (UNCG). Library ID10898.

Nemeth, C., Mosier, K., \& Chiles, C. (1992). When convergent thought improves performance: Majority versus minority influence. Personality \& Social Psychology Bulletin, 18(2), 139-144.

O'Reilly, T. (2007). What is Web 2.0: Design patterns and business models for the next generation of software. Communications \& Strategies, 65, 17-37. 
Orlikowski, W. J., \& Baroudi, J. J. (1991). Studying information technology in organizations: Research approaches and assumptions. Information Systems Research, 2(1), 1-28.

Parameswaran, M., \& Whinston, A. (2007, January). Social computing: An overview. Communications of the Association for Information Systems, 19(37), 762-780.

Richards, D. (2009). A social software/Web 2.0 approach to collaborative knowledge engineering. Information Sciences, 179(15), 2515-2523.

Salas, E., Burke, C. S., \& Cannon-Bowers, J. A. (2002, January). What we know about designing and delivering team training: Tips and guidelines. In K. Kraiger (Eds.), Creating, implementing and managing effective training and development: State-of-the-Art lessons for practice (pp. 234-262). San Francisco, CA: Jossey-Bass, Inc

Sarker, S., \& Lee, A. (2002). Using a positivist case research methodology to test three competing theories-in-use of business process redesign. Journal of the Association for Information Systems, 2(7), 1-72.

Shanks, G. (2002, November). Guidelines for conducting positivist case study research in information systems. Australasian Journal of Information Systems, 10(1), 76-84.

Wagner, C., (2006). Breaking the knowledge acquisition bottleneck through conversational knowledge management. Information Resources Management Journal, 19(1), 70-83.

Wegner, D. M., Giuliano, T., \& Hertel, P. (1985). Cognitive interdependence in close relationships. In W. J. Ickes (Eds.), Compatible and incompatible relationships (pp. 253-276). New York: Springer-Verlag.

Yin, R. K. (1994). Case study research: Design and method. New York: Sage Publications.

Yin, R. K., (2003). Case study research: Design and Methods (3rd ed.). Thousand Oaks, CA: Sage.

Yoo, Y., \& Kanawattanachai, P. (2001). Developments of transactive memory systems and collective mind in virtual teams. The International Journal of Organizational Analysis, 9(2), 187-208. Https://doi.org/10.1108/eb028933.

Zeng, S., Gonzalez, J., \& Lobato, C. (2015). The effect of organizational learning and Web 2.0 on innovation. Management Decision, 53(9), 2060-2072. 